\title{
Management of thyroid cancers
}

\author{
Devendra A. Chaukar · Anuja D. Deshmukh · Mitali R. Dandekar
}

Received: 5 October 2009

Accepted: 20 February 2010

(C) Indian Association of Surgical

Oncology 2010

Devendra A. Chaukar $(\square)$.

Anuja D. Deshmukh .

Mitali R. Dandekar

Department of Head and Neck Surgery,

Tata Memorial Hospital,

Dr. Ernest Borges Road,

Mumbai 400 012, India

e-mail: dchaukar@gmail.com

\begin{abstract}
Thyroid cancers cover a large spectrum of disease with diametrically opposite prognosis. At one end of the spectrum we have the well differentiated cancers which carry an excellent prognosis, while at the other end there is anaplastic cancer with high mortality rates and dismal prognosis. Management of thyroid cancers still has some controversial issues due to lack of randomized controlled trials. Extent of surgery, extent of neck dissection, role of radioiodine treatment and thyroid stimulating hormone suppression are still debatable. In this review, we highlight these controversial issues and give guidelines for the management and follow up of patients with thyroid cancer.
\end{abstract}

Keywords Thyroid cancer - Radioiodine treatment - Thyroglobulin

\section{Introduction}

Thyroid cancer, the most common endocrine malignancy, represents approximately $1 \%$ of all human malignancies. In India, its incidence is between $0.8-2$ per $1,00,000$ population. ${ }^{1}$ United states have reported approximately a 2.4-fold increase in the yearly incidence from 1973 to 2002 and this trend appears to be continuing. Moreover, $49 \%$ of the rising incidence consisted of cancers measuring less than $1 \mathrm{~cm} .{ }^{2}$ This is probably due to the increase in detection of asymptomatic nodules by imaging modalities like ultrasonography, computerized tomography (CT) scan and positron emission tomography (PET) scan done for some unrelated indication.

Thyroid cancers cover a large spectrum of disease with diametrically opposite prognosis. At one end of the spectrum we have the well differentiated cancers which carry an excellent prognosis, while at the other end there is anaplastic cancer with high mortality rates and dismal prognosis. Fortunately, majority are well differentiated with papillary and follicular cancers accounting for approximately $79 \%$ and $13 \%$ respectively. ${ }^{3}$ They have a favorable prognosis with survival rates of $90-95 \%$ for papillary carcinoma and $80-85 \%$ for follicular carcinoma.4-6 Medullary carcinoma, arising from parafollicular $\mathrm{C}$ cells accounts for $3-5 \%$ and carries a less favorable prognosis with a 10 year survival of approximately $65-80 \%{ }^{7}$ Anaplastic carcinoma is rare and accounts for $2-5 \%$ with a poor prognosis.

\section{Management of well differentiated cancers}

These tumors arise from the follicular cells and most common histologies are the papillary and follicular carcinomas. Despite their difference in behavior (Papillary is multicentric and prone to lymphatic spread with high incidence of nodal metastasis, follicular spreads by the hematogenous route with greater incidence of distant metastasis) they carry an excellent prognosis. Certain variants of papillary cancers such as the tall cell, columnar or diffuse sclerosing variant are more aggressive in behavior. Hurthle cell carcinoma which is a variant of follicular cancer has a behavior similar to it. ${ }^{8}$

In oncology the intensity of treatment must match the aggressiveness of the cancer. Due to the overall excellent prognosis of majority of well differentiated cancers and 
the lack of prospective randomized trials, the management of these cancers generates tremendous controversy. Debate exists at every step in the management from the extent of initial surgery; the role of Radioactive-iodine (RAI), degree of Thyroid Stimulating Hormone (TSH) suppression and long term follow up.

We will divide the management into the following: (1) Work-up of a thyroid nodule; (2) Extent of surgery; (3) Role of post-operative RAI scanning; (4) Role of Thyroglobulin (Tg); (V) Role and extent of TSH suppression and follow-up; (VI) Role of external beam radiotherapy (EBRT)

\section{Work-up of thyroid nodule}

Most well differentiated cancers present as thyroid nodule. The incidence of malignancy in patients with a solitary nodule and multiple nodules is the same. ${ }^{9-10}$ In a person presenting with a thyroid nodule it is important to ascertain whether malignancy exists. Family history of cancer and exposure to radiation in the past increase the likelihood of malignancy. Malignancy is more common at extremes of age, in male sex and in a firm to hard nodule. The following three tests are done in all cases of thyroid nodule, namely thyroid function test (TFT), ultrasonography (USG) and fine needle aspiration cytology (FNAC).

TFT: A low TSH is an indication to perform a thyroid scan as hot or functioning nodules are rarely malignant and an FNAC may be avoided.

USG: Can characterize the nodule and differentiate solid from cystic swelling. Hypoechogenecity, irregular margins, presence of punctate calcification, large size and absence of halo are some indicators of malignancy. FNAC can be targeted.

$F N A C$ : It has a high diagnostic value with a low false positive rate. ${ }^{11}$ It can classify the nodule as malignant, suspicious for malignancy or benign. It has greater accuracy in diagnosing a papillary carcinoma. It cannot distinguish a follicular adenoma from a carcinoma as vascular and capsular invasion needs to be demonstrated to make the diagnosis.

\section{Extent of surgery}

Debate regarding lobectomy versus total thyroidectomy is ongoing for the past few decades and is unlikely to resolve. Various prognostic scoring systems (Table 1) were devised, trying to club patients into a low-risk and high risk group. Some of the commonly used staging systems are the TNM, AGES, AMES, DAMES, and MACIS.
The main prognostic factors in these classifications were age, size of tumor, grade, presence or absence of extrathyroidal spread, distant metastasis and completeness of surgery. These staging systems based on multiple regression analysis of combined prognostic factors helped in assessing an individual's risk of mortality and helped treatment planning. The staging systems have many drawbacks:

- There are about 17 different classifications, some of which have included patients with only papillary cancers, some include papillary and follicular cancers while a few have included other aggressive histologies like medullary and anaplastic cancers thus making it a heterogeneous group.

- Aggressive variants such as tall cell and columnar cell cancers are not accounted for.

- The effects of recurrence and its impact on quality of life are not accounted for.

The major criticism is that the surgeon may not be aware of all the parameters pre-operatively and hence the prognostic systems do not help him to take a decision regarding the extent of initial surgery. These systems help in prognostication and deciding the need for aggressive post - operative therapy such as radio-iodine ablation and the degree of TSH suppression.

However, majority of the patients can be classified into a low risk group which included young patients with small, well-differentiated intrathyroidal tumors and no evidence of nodal or distant spread; their prognosis is excellent, with cancer - specific mortality of less than $1-2 \%{ }^{12-13}$ High-risk group, which includes older patients with locally advanced or metastatic disease at presentation or poorly differentiated tumors, have a 20 year survival of $57 \%-60 \%{ }^{14}$ Risk-group analysis makes a selective approach to management possible and can spare many patients of the morbidity of unnecessary aggressive treatment without compromising outcome. A hemithyroidectomy or lobo-isthumectumy is adequate in low risk patients while the high risk patients need a total thyroidectomy. However management of well differentiated tumors is not as simple as it appears to be from the preceding discussion. Grant et al. reported a higher risk of recurrence even in the low risk group who underwent a unilateral excision (14\%) as compared to those with bilateral resections $(2 \%) .{ }^{15}$ Shaha et al. ${ }^{16}$ defined a intermediate risk group which consisted of young patients with high risk tumor factors and older patients with low risk tumor factors. They demonstrated an intermediate survival of $86 \%$ for this group that was between low risk (99\%) and high risk (56\%). The debate is most intense for this group of patients.

The debate: Hemi-thyroidectomy versus total thyroidectomy. 
Table 1. Most widely used scoring systems and their calculations

\begin{tabular}{|c|c|c|}
\hline \multicolumn{3}{|l|}{ AGES } \\
\hline \multicolumn{2}{|c|}{ Prognostic score $=0.05 \times$ age (if age $\geq 40$ years $)$} & Survival by AGES score (20-year) \\
\hline \multicolumn{2}{|c|}{$+1($ if grade 2$)$} & $<3.99=99 \%$ \\
\hline \multicolumn{2}{|c|}{+3 (if grade 3 or 4$)$} & $4-4.99=80 \%$ \\
\hline \multicolumn{2}{|c|}{+1 (if extrathyroid) } & $5-5.99=67 \%$ \\
\hline+3 (if dis & & $>6=13 \%$ \\
\hline \multicolumn{3}{|c|}{$+0.2 \times$ tumor size $(\mathrm{cm}$ in max. diameter $)$} \\
\hline \multicolumn{2}{|l|}{ AMES } & Survival AMES risk groups (20-year) \\
\hline \multirow[t]{6}{*}{ Low-risk: } & Younger patients $($ men $<40$ years, & Low-risk $=99 \%$ \\
\hline & women $<50$ years, No metastases & High-risk $=61 \%$ \\
\hline & Older patients (intrathyroid papillary, & \\
\hline & minor capsular invasion, for follicular & \\
\hline & lesions) Primary cancers $<5 \mathrm{~cm}$ & \\
\hline & No distant metastasis & \\
\hline \multirow[t]{4}{*}{ High-risk: } & All patients with distant metastasis & \\
\hline & Extathyroid papillary, major capsular & \\
\hline & invasion for follicular lesions & \\
\hline & Primary cancers $>5 \mathrm{~cm}$ in older patients & \\
\hline \multicolumn{2}{|l|}{ MACIS } & Survival by MACIS score (20-year) \\
\hline \multirow[t]{6}{*}{ Score $=3.1$} & (if age $<40$ years) or & $<6=99 \%$ \\
\hline & $0.08 \times$ age (if age $>40$ years) & $6-6.99=89 \%$ \\
\hline & $+0.3 \times \mathrm{T}$ size $(\mathrm{cm}$ max. diameter $)$ & $7-7.99=56 \%$ \\
\hline & + 1 (if incompletely resected) & $8+=24 \%$ \\
\hline & +1 (if locally invasive) & \\
\hline & +3 (if distant spread) & \\
\hline
\end{tabular}

\section{Arguments for total thyroidectomy}

- Bilateral cancers are common (30-85\%)

- Reduces recurrence in all risk groups

- Morbidity is much the same as that with lobectomy

- Enhances ability to use Iodine ${ }^{131}$

- Lower dose for ablation

- Enhances recurrence monitoring

- Enhance use of thyroglobulin monitoring for recurrence

\section{Argument for Hemi - thyroidectomy}

- Most patients have low - risk cancer and excellent prognosis

- Role of adjuvant treatment is not defined

- Occult multicentric tumors are not clinically important

- Increased risk of complications with total thyroidectomy

- Recurrence in opposite lobe arises in less than $5 \%$ of patients

- Most local recurrences can be treated with surgery

- Excellent long-term outcome with lobectomy alone in low-risk patients.

\section{Take home message}

(1) Hemithyroidectomy in patients with tumors $<1.5 \mathrm{~cm}$ with no extra-thyroidal spread and no distant metastasis

(2) Total thyroidectomy in all high risk patients, i.e. tumors $>4 \mathrm{~cm}$, age $>45$ years, extrathyroidal disease, distant metastasis, prior history of radiation to the neck and unfavorable histology.

The main debate is for tumors between $1.5 \mathrm{~cm}-4 \mathrm{~cm}$ in size with no other high risk features. Therapy should be individualized depending on the expertise available. A survey in 1500 US hospital reported that $77 \%$ surgeons prefer a total thyroidectomy. ${ }^{17}$

\section{Extent of Lymphadenectomy}

The incidence of nodal metastasis is high in patients with papillary carcinoma. Nodal metastasis is not considered to have an impact on overall survival. ${ }^{18-19}$ However recent studies have demonstrated nodal metastasis in high risk groups to be a significant indicator of prognosis. ${ }^{20-21}$ Noguchi et al in 1990 showed that lymph node metastasis was an independent risk factor. ${ }^{22}$ In all patients with pap- 
illary carcinoma, central compartment nodes (along the recurrent nerve, level VI) must be sampled as nodal recurrence in the central compartment is difficult to treat. Lateral compartment is dissected (level II-IV), if grossly enlarged nodes are present or USG has demonstrated nodal disease. There is no role for 'berry picking'. Inadequate neck surgery results in revision neck dissection as nodal disease is not sterilized adequately by radioiodine.

\section{Pediatric thyroid cancers}

Thyroid cancers in children are rare accounting for less than $5 \%$ of all thyroid cancers. ${ }^{23}$ Their biological behavior is different from that of adult patients. They are more advanced at presentation with a high incidence of lymph nodal and pulmonary metastasis. ${ }^{24}$ Pulmonary metastasis can be missed in the initial X-ray in approximately $30 \%$ of the patients and are picked up only on RAI scanning. Lymph nodal metastasis at presentation is a harbinger of distant metastasis. ${ }^{25}$ Hence, total thyroidectomy with neck dissection and post operative RAI is the treatment of choice in majority of the patients except in a few selected patients with low risk where hemithyroidectomy is advocated.

\section{Role of Radio - iodine administration}

Following total thyroidectomy, some amount of residual thyroid tissue is left behind in majority of cases. The aim of RAI therapy is to ablate the remnant tissue as this facilitates pick up of metastatic disease. It is also given as adjuvant therapy to destroy unproven but suspected metastatic disease and as a therapy for proven residual or recurrent disease. It also improves the sensitivity and specificity of thyroglobulin as a marker of recurrent or metastatic disease in the post-operative period. The indications of RAI therapy are controversial as it may not be necessary in some patients. Patients with unifocal, less than $1 \mathrm{~cm}$ sized tumors with no extrathyroidal spread and negative nodes carry an excellent prognosis with surgery alone and routine use of RAI is not advocated in these patients. In patients with high risk factors for local recurrence (older patients, $>4 \mathrm{~cm}$ tumor, extrathyroidal spread, extranodal spread) or in patients with aggressive histologies and distant metastasis, RAI therapy significantly reduces the cancer specific mortality. ${ }^{26-28}$ The debate is intense in patients with tumors between $1.5 \mathrm{~cm}$ and $4 \mathrm{~cm}$ in size without any other high risk factors. Mazzaferri observed a recurrence rate of $16 \%$ in 350 patients treated with RAI therapy for a primary tumor $>1.5 \mathrm{~cm}$ in diameter, significantly lower $(P$ value $<$ $0.001)$ than $38 \%$ rate in 802 patients treated with levothyroxine (L-T4) alone. ${ }^{29}$ There were also fewer deaths in patients treated with RAI (3\% vs $8 \%$ ). However these favorable results were not confirmed by a similar type of analysis done at the Mayo clinic. ${ }^{30}$

\section{Protocol for administration}

To optimize uptake, radioiodine is administered following TSH stimulation. Thyroid hormone supplementation is withheld and iodine contamination carefully avoided for 4-6 weeks after surgery. Serum TSH should be above an empirically determined level of $>25-30 \mu \mathrm{U} / \mathrm{ml}$ before administration of ${ }^{131} \mathrm{I}$. Pregnancy should be excluded in women of childbearing age. To decrease the side effects of thyroid hormone withdrawal, $\mathrm{LT}_{3}$ can be administered followed by withdrawal for two weeks. Recombinant TSH (Thyrogen, rTSH), is a viable alternative to thyroid hormone withdrawal, and has been shown to have comparable efficacy to hormone withdrawal. ${ }^{31}$ Currently, the high cost is a limiting factor. It particularly benefits patients with cardiac or respiratory co-morbidities or patients with life or limb threatening metastasis.

\section{Thyroglobulin (Tg)}

Thyroglobulin is synthesized by the thyroid follicular cells and specifically represents thyroid tissue. It is a reliable and specific indicator of the presence of thyroid epithelial cells, either benign or malignant. ${ }^{32}$ Serum measurements are done by using either immunometric or radioimmunoassays. Inter-method differences mandate Tg measurement to be done by the same assay and ideally in the same laboratory at follow-up. Tg-antibodies $(\mathrm{TgAb})$ are present in $25 \%$ of patients and may interfere with $\mathrm{Tg}$ measurements. Presence of $\mathrm{TgAb}$ may yield falsely low, undetectable or high values of Tg depending on the assay used. Hence $\mathrm{TgAb}$ should be measured in all patients prior to Tg analysis. ${ }^{33}$ Measurement of TgAb has been demonstrated to be an independent prognostic indicator of the efficacy of treatment. Persistence of TgAb or increase in their levels may indicate an increased risk of recurrence. A downward trend and disappearance of $\mathrm{TgAb}$ may be a positive indicator of treatment efficacy. ${ }^{34}$

$\mathrm{Tg}$ is a sensitive and specific marker following complete ablation of the thyroid gland for recurrent or metastatic disease. TSH is the most important regulator of $\mathrm{Tg}$ and hence $\mathrm{Tg}$ values should be interpreted with knowledge of corresponding $\mathrm{TSH}$ values. Serum $\mathrm{Tg}$ measurements are most sensitive when patients are no longer receiving thyroid hormone and $\mathrm{TSH}$ levels are elevated. ${ }^{35}$ To avoid side effects of hypothyroidism rTSH administration has been used to measure stimulated $\mathrm{Tg}$ values. $^{36}$ There is no cut-off value of Tg to decide presence of recurrent or metastatic disease. Torrens et al. reported that risk of relapse increased significantly when 


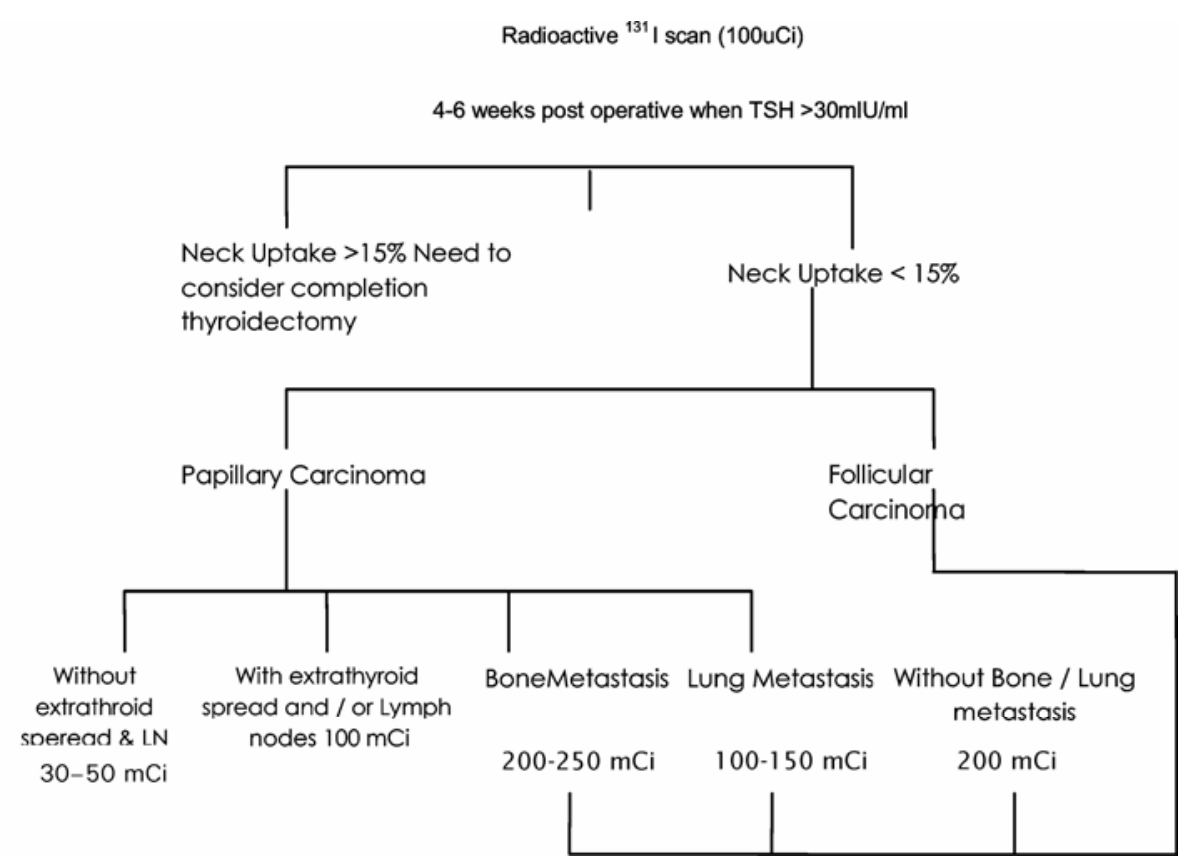

TSH suppressed Tg levels were $>10 \mathrm{ng} / \mathrm{ml}$. Recurrent disease was seen in $4 \%$ of patients with $\mathrm{Tg}<10 \mathrm{ng} / \mathrm{ml}$, $21 \%$ with $\mathrm{Tg}>10 \mathrm{ng} / \mathrm{ml}$ and $43 \%$ in patients $\mathrm{Tg}$ $>30 \mathrm{ng} / \mathrm{ml}^{37}$

\section{Take home message}

- Measurement of Tg in preoperative setting is not recommended.

- $\mathrm{Tg}$ is a reliable marker for recurrent and metastatic disease following total thyroidectomy and RAI ablation.

- It should be measured 3 months following surgery and sometimes may take up to 1 year to be undetectable.

- $\mathrm{Tg}$ Ab screening should be done in all cases and Tg should be measured in the same laboratory with the same assay method.

- TSH levels to be correlated with Tg.

- No consensus if Tg has to be measured 'on' or 'off' eltroxin. However Tg levels are most sensitive when TSH is raised.

- Serial measurement is better than an isolated value.

\section{L-T $\mathrm{T}_{4}$ therapy and TSH suppression}

Following total thyroidectomy and iodine ablation, all patients receive ${\mathrm{L}-\mathrm{T}_{4}}_{4}$ therapy. The aim is to correct the surgically induced hypothyroidism and to suppress TSH.

\section{Thyroid hormone replacement}

$\mathrm{L}-\mathrm{T}_{4}$ is the drug of choice as it has a long half life, is associated with stable $T_{3}$ levels and is a more effective
Table 2. Dose of L-tetraiodothyronine required to obtain low serum thyroid- stimulating hormone levels in athyreotic patients

\begin{tabular}{ll}
\hline Dose $(\mu \mathrm{g} / \mathrm{kg})$ & Age \\
\hline $3-4$ & Children \\
$2.5-2.2$ & Adults \\
$1.4-1.2$ & Elderly \\
\hline
\end{tabular}

regulator of TSH than $\mathrm{T}_{3} . \mathrm{LT}_{4}$ is administered as a single dose due to its long half life (6-8 days). As food intake reduces its absorption, $\mathrm{LT}_{4}$ is administered before breakfast on an empty stomach. The dose (Table 2) depends on the body weight or more accurately on the lean body mass (Athletes may require higher dose per kg body weight than obese individuals). The dose is titrated as per the requisite TSH level. To avoid iatrogenic thyrotoxicosis, the serum $\mathrm{T}_{3}$ levels should be within normal range and the free $T_{4}$ level is around the upper limit of normal. ${ }^{38-39}$

\section{TSH suppression}

Differentiated thyroid cancers contain membrane receptors for TSH and hence are responsive to TSH stimulation, providing rationale for TSH suppression therapy. Various studies have demonstrated an increase in tumor growth in hypothyroid patients. ${ }^{40-42}$ Mazzaferri demonstrated better control rates when $\mathrm{T}_{4}$ suppression was combined with RAI. Recurrence rates reduced from $50 \%$ to $10 \%{ }^{43}$

There is a general consensus that TSH suppression by $\mathrm{T}_{4}$ decreases risk of recurrence and improves overall prognosis. However two important questions need to be addressed: 
1. Is TSH suppression required for all patients with well differentiated cancers?

2. What is the optimal suppression level?

Although $\mathrm{T}_{4}$ is considered virtually innocuous, it has the potential to cause reduction in bone density in postmenopausal women. ${ }^{4-46}$ A study by Bindoi et al. in patients on $\mathrm{LT}_{4}$ suppressive therapy demonstrated its potential to cause marked impairment in cardiac functional reserve and physical exercise capacity. ${ }^{47}$ Thus long term suppressive therapy may not be as harmless as thought to be and it is particularly associated with increased cardiovascular mortality in the elderly. ${ }^{48}$

Wang et al. studied optimal TSH suppression by analyzing the relationship between $\mathrm{TSH}$ suppression and $\mathrm{Tg}$ response with titration of the dosage of T4. Patients were divided into three groups. Group A had patients with clinically evident disease, group B patients had no evidence of clinical disease but a raised $\mathrm{Tg}$ and group $\mathrm{C}$ had no evidence of clinical or biochemical disease.

During $\mathrm{L}_{-} \mathrm{T}_{4}$ therapy, within the same treatment course, mean Tg levels were higher when TSH levels were normal than when TSH levels were suppressed, statistically significant in group A $(P=0.001)$, nonsignificant in group $\mathrm{B}(P=0.09)$, and nonsignificant in group $\mathrm{C}(P=0.03) .{ }^{49}$

The data suggested a stratified postoperative thyroid hormone management of patients with differentiated thyroid carcinoma. TSH should be lowered to below normal in patients with active disease. If patients are clinically disease free with Tg levels below $2 \mathrm{ng} / \mathrm{ml}$, TSH can be kept within the normal range. For the most controversial group B patients, it is recommended that the TSH be suppressed and be closely followed up.

In patients with low risk of recurrence i.e. complete tumor removal, size $<1.5 \mathrm{~cm}$, no uptake outside thyroid bed, no evidence of disease on ultrasonography and undetectable $\mathrm{Tg}$ on 6-12 months follow-up, favorable results are obtained even with TSH in the normal range. ${ }^{50-51}$ Therefore, patients with low risk can be identified within the first year and in this group of patients, there is no need for long-term suppressive therapy. In patients with high risk factors the TSH level must be below $0.01 \mu \mathrm{U} / \mathrm{mL}$ as tolerated without hyperthyroid symptoms. ${ }^{52-54}$ In patients with tumor size between $1.5 \mathrm{~cm}-$ $4 \mathrm{~cm}$ with no other high risk factors, there is a debate regarding the need and extent of suppression required. The current guidelines recommend suppression to lower limit of normal, i.e. $0.05-0.1 \mu \mathrm{U} / \mathrm{ml}^{56}$

\section{Take home message}

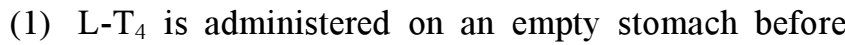
breakfast.

(2) In high risk group, TSH levels must be maintained below $0.01 \mu \mathrm{U} / \mathrm{ml}$. In intermediate and low risk groups, TSH levels are maintained between $0.05-0.1 \mu \mathrm{U} / \mathrm{ml}$.

\section{Role of EBRT in differentiated cancers}

The role of EBRT is controversial as the current data is based on retrospective studies which limit our ability to draw definite conclusions. In low risk tumors, EBRT provides no additional advantage and has no role in the management of these tumors. It is indicated in patients with inoperable tumors or in patients with gross residual disease. Recent series have consistently reported a favorable impact on loco-regional control. ${ }^{57}$ Tubina et al. ${ }^{58}$ reported on 163 patients with either microscopic or gross residual disease following surgery; the 15 year locoregional control was $89 \%$ after EBRT compared with $67 \%$ after surgery and radioactive iodine. Chow et al. ${ }^{59}$ demonstrated a 10 year local control rate of $56.2 \%$ in patients receiving EBRT versus $24 \%$ in patients without EBRT in a cohort of patients with gross residual neck disease. The controversy is greatest in patients with minimal residual disease showing RAI uptake and in those with a high risk of local recurrence (older patients, extrathyroidal spread, multiple nodes with perinodal disease, large tumor size). Phillips et al. ${ }^{60}$ reported 94 patients with minimal residual disease or lymph node involvement with extranodal spread. Those treated with standard therapy had a relapse rate of $21 \%$ as compared to $3 \%$ in those who were also treated with EBRT. Farahat et al. ${ }^{61}$ demonstrated improved loco-regional control and decreased distant metastasis in patients over the age of 40 with papillary cancer, extrathyroid extension and lymph node involvement treated with EBRT. These results strongly recommend EBRT in patients with high risk of local recurrence. However the data is insufficient to make any definite recommendation and the decision to treat with EBRT should be made on case to case basis weighing the advantages with the potential risks and sideeffects. In cases where uptake of radioiodine is absent, EBRT may play a role in achieving local control. Although surgical resection and high doses (therapeutic) of RAI are the options available, EBRT has been shown to be effective. Simpson et al reported a disease free survival of $90 \%$ in patients with microscopic residual papillary cancer treated with EBRT as compared to $26 \%$ in patients treated with surgery alone. EBRT has a definite role to play in the palliation of distant metastasis, mainly to the brain and bones.

\section{Take home message}

- No role in low risk tumors.

- EBRT at doses of 60-70 Gy over a period of 6-7 weeks is effective in patients with inoperable or gross residual tumors.

- Palliation of distant (bone and brain) metastasis.

- In patients with high risk of local relapse (Extranodal spread, gross extrathyroidal extension, microscopic 
residual disease) it may improve local control. However the evidence to support this is not robust and a decision should be made on an individual basis.

- Patients with radio-iodine resistant progressive disease may benefit from the addition of EBRT.

\section{Follow up}

All patients are routinely followed up every 3-6 monthly for the first 2 years and yearly thereafter. Follow up includes a thorough clinical examination which maybe corroborated with sonography of the neck. Serial $\mathrm{Tg}$ estimation is a specific indicator of disease control in patients operated with total thyroidectomy. It is complemented with $\mathrm{I}^{131}$ whole body scan (WBS) and ablation if required after adequate thyroid hormone withdrawal. $\mathrm{I}^{131}$ WBS is recommended till 2 consecutive scans show no uptake. There are conditions in which $\mathrm{Tg}$ is elevated with negative WBS (Thyroglobulin Elevated Negative Iodine Scan, TENIS syndrome). In such situations, non radioiodine imaging modalities like CT scan or PET may detect recurrence or metastasis.

\section{Recurrence}

High risk thyroid cancers have a higher rate of recurrence between $20-30 \%$ in some studies. ${ }^{62}$ About $85 \%$ of patients have cervical nodal metastasis, $32 \%$ have local recurrence in the thyroid bed and $12 \%$ have distant metastasis. After detection of locoregional recurrence by clinical examination or by the above investigations, surgical resection is the preferred method of treatment followed by RAI therapy. ${ }^{63}$ In cases of recurrence detected only by WBS, RAI ablation maybe an option. Also in TENIS syndrome, empirical therapeutic doses of $\mathrm{I}^{131}$ have been found to be beneficial. ${ }^{64}$ The theory behind this is that micrometastasis are too small to be detected by low dose WBS which may still take up some iodine. ${ }^{65-66}$

\section{Metastasis}

Metastatic disease with Iodine avidity should be subjected to RAI therapy. Asymptomatic non Iodine avid metastasis can be observed with TSH suppression alone. ${ }^{52}$ In solitary metastasis especially in weight bearing areas of the skeletal system or central nervous system, surgery is preferred. EBRT is used for palliation in painful bone metastasis or grossly unresectable disease. ${ }^{67}$

\section{Completion thyroidectomy}

Completion surgery is considered in patients who have been operated previously and have high risk factors.
Treatment of intermediate risk patients should be individualized. Minimum surgery for a thyroid lesion should be a hemithyroidectomy to facilitate completion thyroidectomy if required.

\section{Management of locally invasive well differentiated thyroid cancers}

Incidence of invasion of the upper aerodigestive tract by well differentiated thyroid carcinoma is less than $4 \%{ }^{68}$ Shin $^{69}$ and coworkers have attempted to provide classification for locally invasive thyroid carcinoma as follows:

Stage 0: Confined to the substance of the thyroid gland. Stage 1: Extends through capsule of the thyroid gland and abuts external perichondrium but does not erode cartilage or invade between cartilaginous plates.

Stage 2: Invades between rings of cartilage or destroys cartilage.

Stage 3: Extends through the cartilage or between the cartilaginous plates into the lamina propria of the tracheal mucosa but does not elevate or invade the epithelium.

Stage 4: Extends through the entire thickness, expands the tracheal mucosa and is visible through a bronchoscope as a nodule or ulcerated mass.

Treatment depends whether there is intraluminal involvement.

Shave excision of the disease is advocated in case of cartilage involvement without gross intraluminal extension. 'Shaving' is described as removal of all gross tumour by resection of partial thickness of the aerodigestive tract wall with an assumption that microscopic foci of tumour remains. ${ }^{68}$ This approach has been shown in many studies to be as effective with locoregional control as complete resection without morbidity of extensive procedures that affect swallowing, speech and voice. However, there have been studies which showed that there was a high recurrence rate of thyroid carcinoma invading the airway after 'shaving' of disease. ${ }^{70-71}$ If there is intraluminal extension then complete resection with appropriate reconstruction of the larynx, trachea or pharynx is required pre-existing recurrent laryngeal nerve paralysis requires resection of the nerve with the tumour in nearly all cases. When preoperatively the vocal functions are normal with tumour encasement seen on table an attempt should be made to carefully shave off the disease from the nerve. However, it could cause temporary or permanent vocal fold paralysis. ${ }^{68}$

Major contraindications to thyroid tumour resection include:

(i) Massive tracheal or esophageal invasion beyond reconstructive capacity. 
(ii) Innominate artery invasion.

(iii) Deep invasion into the mediastinum.

In case of gross residual disease EBRT can be effective in controlling locoregional disease. ${ }^{72}$

\section{Medullary thyroid cancer}

Medullary thyroid cancer (MTC) is a rare neuroendocrine tumour accounting for $5 \%$ of all thyroid cancers. It is derived from parafollicular $\mathrm{C}$ cells and secretes Calcitonin. 5 year survival ranges from $80-85 \%$ and 10 year survival is $70-80 \%{ }^{73}$

MTC can either be sporadic (80\%) or familial (20\%).

Familial MTC have autosomal dominant inheritance. They have an earlier age of presentation than sporadic MTC and show multifocality.

\section{Types}

(1) Familial MTC: less aggressive type.

(2) MEN 2a: associated with pheochromocytoma (50\% penetrance) and hyperparathyroidism (10-20\% penetrance). It maybe associated with cutaneous lichen amyloidosis or Hirschsprung's disease.

(3) MEN 2b: associated with pheochromocytoma (50\% penetrance), marfanoid habitus, ganglioneuromas of the gut and oral mucosa ( $>90 \%$ penetrance). It is the most aggressive type.

$25-50 \%$ of the individuals of MTC present with cervical metastasis and it is independent of the size of the primary tumour. $^{74}$ Incidence of distant metastasis is highest for MEN 2b (20\%) followed by sporadic (12\%), MEN 2a $(3.3 \%)$ and least for familial MTC $(2 \%){ }^{75}$

Table 3. Clinical syndrome and associated mutated codon of RET

\begin{tabular}{lcl}
\hline Clinical syndrome & Exon & \multicolumn{1}{c}{ Codons } \\
\hline MEN 2A & 10 & $609,618,620$ \\
MEN 2B & 11 & 634 \\
& 16 & 918 \\
FMTC & 15 & 883 \\
& 10 & $611,618,620$ \\
& 11 & 634 \\
& 13 & 768,791 \\
& 14 & 804 \\
8 & 533 \\
\hline
\end{tabular}

Diagnosis is made with a FNAC, serum Calcitonin levels and immunohistochemistry with Calcitonin if required. CT thorax is performed to rule out mediastinal nodes. All patients of MTC should undergo screening for RET proto oncogene because patients with no family history maybe index cases. ${ }^{76}$ Clinical syndrome and associated mutated codon of RET is tabulated (Table 3). RET proto oncogene testing helps in screening other family members having mutations and thus plan a prophylactic thyroidectomy. Patients who harbour mutation to RET proto oncogene need further work up to rule out distant metastasis with PET, pheochromocytoma with urinary metanephrines and hyperparathyroidism with serum calcium and parathormone levels.

\section{Treatment}

Surgery is the mainstay of treatment as the tumour does not take up RAI. Total thyroidectomy is advocated for both sporadic and familial MTC in view of multifocality. Central compartment clearance from the hyoid bone to the innominate artery is performed and bilateral lateral neck sampling is performed. Depending on mediastinal nodes, mediastinal clearance is performed.

Surgery has a role to play even in metastatic disease as it offers the best palliation and better survival if morbidity of surgery is not much.

Adjuvant radiotherapy is indicated for gross residual disease, extrathyroidal extension, perinodal extension, recurrent or unresectable disease. EBRT does not increase survival but reduces locoregional recurrence.

Systemic chemotherapy in view of distant metastasis has shown limited efficacy. Most commonly used drugs include doxorubicin, dacarbazine, 5-fluorouracil and streptozocin.

\section{Role of prophylactic thyroidectomy}

According to ATA guidelines ${ }^{77-80}$ three risk levels have been described and recommendations for prophylactic thyroidectomy have been made as follows:

- Highest risk: Mutations associated with MEN2B Total thyroidectomy with lymph node dissection is recommended within the first year of life or as soon as MEN $2 \mathrm{~B}$ is identified.

- High risk mutations associated with MEN 2A (codon $634,611,618,620,630)$ : Thyroidectomy with or without central lymph node dissection by age of 5 years.

- Least high risk: codons 533, 666, 768, 790, 791, 804, 891, 649, 912 No consensus. Some advocate thyroidectomy between 5-10 years. 


\section{Follow up}

Clinical examination, serial serum Calcitonin and periodic USG and CT scan are done to assess recurrent or metastatic disease. In familial MTC, screening for hyperparathyroidism and urinary metanephrines is indicated. In case of elevated serum calcitonin $>500 \mathrm{pg} / \mathrm{ml}$, metastatic workup with a CT scan of neck, chest and abdomen or PET CT is performed. Catheterization of superior vena cava and internal jugular vein to localize the tumor was done by Frank-Raue $\mathrm{K}$ et al. ${ }^{79}$ If resectable disease is detected, then surgery is performed. In case of no identifiable disease, Tisell et al. advocated meticulous 12-hour microdissection with reoperation to normalize serum calcitonin levels in up to $30 \%$ patients. ${ }^{81}$ However, it has shown no survival benefit. We advocate close follow up of such patients. EBRT and chemotherapy is reserved for palliation in symptomatic metastatic disease. Somatostatin analogues help in patients with symptoms of diarrhea and flushing. Targeted radiotherapy and chemotherapy has been tried with doubtful benefit. ${ }^{82}$

\section{Management of anaplastic cancer}

They can either arise denovo or can dedifferentiate from well differentiated thyroid cancer.

The prognosis of patients with any element of anaplasia within a differentiated thyroid cancer was no different from patients with anaplastic tumour throughout according to the analysis of EORTC thyroid cancer study group. ${ }^{83}$

Complete surgical resection is the best chance of cure. Total thyroidectomy is justified if cervical and mediastinal disease can be resected with limited morbidity. ${ }^{84}$

Majority of patients present in an advanced stage. Tracheostomy is performed for palliation. Although anaplastic cancer is relatively radioresistant, radiotherapy is the mainstay for local control and palliation. There has been little evidence to show that anaplastic carcinoma is chemosensitive. However in view of the high incidence of distant metastasis, chemotherapy is fundamental in the treatment The chemotherapeutic agents tried are doxorubicin, cisplatin, paclitaxel. ${ }^{85-86}$

\section{References}

1. Parkin D, Muir C, Whelan S, Gao Y, Fenlay J, Powell J. Cancer incidence in five continents. Lyon: IARC Scientific Publication International Agency for Research on Cancer, nd.

2. Davies L, Welch HG. Increasing incidence of thyroid cancer in the United States, 1973-2002. JAMA. 2006;295:2164-2167.

3. Hundhal SA, Fleming ID, Fremgen AM, Menck HR, et al. A National Cancer Data Base report on 53,856 case of thyroid carcinoma treated in the US, 1985-1995. Cancer. 1998; 83(12):2638-2648

4. Mazzaferri EL, Young RL. Papillary thyroid carcinoma: a ten-year follow-up report on the impact of treatment in 576 patients. Am J Med. 1981;70:511-8

5. Emmerick G, Duh Q, Siperstein A, Burrow G, Clark O. Diagnosis, treatment, and outcome of follicular carcinoma. Cancer. 1993; 72(11): 3287-95

6. Shaha A, Loree TR, Shah JP. Prognostic factors and risk group analysis in follicular carcinoma of the thyroid. Surgery. 1995;118:11311138.

7. Duh QY, Sancho JJ, Greenspan FS, Hunt TK, Galante M, deLorimier
AA, et al. Medullary thyroid carcinoma: the need for early diagnosis and total thyroidectomy. Arch Surg. 1989;124:1206-1210

8. Carcangiu ML, Bianchi S, Savino D, Voynick IM, Rosai J. Follicular Hurthle cell tumors of the thyroid gland. Cancer. 1999;68:1944-53.

9. Marqusee E, Benson CB, Frates MC, Doubilet PM, Larsen PR, Cibas ES, et al. Usefulness of ultrasonography in the management of nodular thyroid disease. Ann Intern Med. 2000; 1339:696-700

10. Papini E, Guglielmi R, Bianchini A, Crescenzi A, Taccogna S, Nardi F, et al. Risk of malignancy in nonpalpable thyroid nodules: predictive value of ultrasound and colorDoppler features. J Clin Endocrinol Mrtab. 2002;87:1941-1946.

11. Campbell JP, Pillsbury HC. Management of the thyroid nodule. Head Neck. 1989;11:414-25.

12. Mazzaferri EL, Jhiang SM. Long term impact of initial surgical and medical therapy on papillary and follicular thyroid cancer. Am J Med. 1994; 97:418-28.

13. Hay ID, Grant CS, van Heerden JA, Goellner JR, Ebersold JR, Bergstralh EJ, et al. Papillary thyroid microcarcinoma: a study of 535 cases ob- served in a 50-year period. Surgery 1992;112:1139-47.

14. Taylor T, Specker B, Robbins J, Sperling $\mathrm{M}$, Ho $\mathrm{M}$, Ain $\mathrm{K}$, et al. Outcome after treatment of high risk papillary and non-Hurthle cell follicular thyroid carcinoma. Ann Intern Med. 1998;129:622-27.

15. Hay ID, Grant CS, Bergatralh EJ, Thompson GB, van Heerden JA, Goellner JR. Unilateral total lobectomy: Is it sufficient surgical treatment for patients with AMES lowrisk papillary thyroid carcinoma. Surgery. 1998;124:958-66.

16. Shaha AR, Loree TR, Shah JP. Intermediate-risk group for differentiated carcinoma of thyroid. Surgery. 1994;116:1036-41.

17. Massin JP, Savoie JC, Garnier H, Guiraudon G, Leger FA, Bacourt F. Pulmonary metastasis in differentiated thyroid carcinoma. Study of 58 cases with implications for the primary tumor treatment. Cancer. 1984;53(4);982-992.

18. Shaha AR, Shah JP, Loree TR. Risk group stratification and prognostic factors in papillary carcinoma of thyroid. Ann Surg Oncol. 1996; 3:534-8.

19. Hughes CJ, Shaha AR, Shah JP, Loree TR. Impact of lymph node 
metastasis in differentiated carcinoma of the thyroid: a matched-pair analysis. Head Neck. 1996:18:12732.

20. Scheumann GFW, Gimm O, Wegener G, Hundeshagen H, Dralle H. Prognostic significance and surgical management of locoregional lymph node metastasis in papillary thyroid cancer. World J Surg. 1994; 18:559-568.

21. Tisell LE, Nilsson B, Molne J, Hansson $\mathrm{G}$, Fjalling $\mathrm{M}$, Jansson $\mathrm{S}$, et al. Improved survival of patients with papillary thyroid cancer after surgical microdissection. World J Surg. 1996;20:854-859

22. Noguchi M, Kumaki T, Taniya $\mathrm{T}$, Miyazaki I. Bilateral cervical lymph node metastasis in well-differentiated thyroid cancer. Arch Surg. 1990; 125:804-806

23. Fassina AS, Rupolo M. Pelizzo MR, Casara D. Thyroid cancer in children and adolescents. Tumori. 1994; 80:257-262.

24. Newman KD, Black T, Heller G, Azizkhan RG, Vlamis V, Haase GM, et al. Differentiated thyroid cancer: Determinants of progression in patients $<21$ years of age at diagnosis: A report from the surgical discipline committee of the children's cancer Group. Ann Surg. 1998;227:533541

25. Chaukar DA, Rangarajan V, Nair N, D'cruz AK, Nadkarni MS, Pai PS, etal. Pediatric thyroid cancer. J. Surg. Oncol. 2005;92:130-133.

26. Taylor T, Specker B, Robbins J, Sperling $\mathrm{M}$, Ho $\mathrm{M}$, Ain $\mathrm{K}$, et al. Outcome after treatment of highrisk papillary and non-Hurthlecell follicular thyroid carcinoma. Ann of Intern Med. 1998;129:622627

27. Tsang RW, Brierley JD, Simpson WJ, Panzarella R, Gospodarowicz MK, Sutcliffe SB. The effects of surgery, radioiodine and external radiation therapy on the clinical outcome of patients with differentiated thyroid carcinoma. Cancer. 1998; 82:375-388.

28. Tubiana $M$, Schlumberger $M$, Rougier P, Laplanche A, Benhamou E, Gardet P, et al. Long-term results and prognostic factors in patients with differentiated thyroid carcinoma. Cancer. 1985;55:794-804.
29. Mazzaferri EL, Kloos RT. Current approaches to primary therapy for papillary and follicular thyroid cancer. J Clin Endocrinol Metab. 2001; 86:1447-1463

30. Wartolsky L, Sherman SI, Gopal J, Schlumberger M, Hay ID. The use of radioactive iodine in patients with papillary and follicular thyroid cancer. J Clin Endocrinol Metab. 1998; 83(4):4195-4203

31. Haugen BR, Pacini F, Reiners C, Schlumberger $\mathrm{M}$, Ladenson $\mathrm{PW}$, Sherman SI, et al. A comparison of recombinant human thyrotropin and thyroid hormone withdrawal for the detection of thyroid remnant or cancer. J Clin Endocrinol Metab. 1999; 84(11):3877-3885.

32. Whitley RJ, Ain KB. Thyroglobulin: a specific serum marker for the management of thyroid carcinoma. Clin Lab Med. 2004;24:29-47.

33. Spencer CA, Takeuchi M, Kazarosyan $M$, Wang $C C$, Guttler $R B$, Singer PA, et al. Serum thyroglobulin autoantibodies: prevalence, influence on serum thyroglobulin measurement, and prognostic significance in patients with differentiated thyroid carcinoma. J Clin Endocrinol Metab. 1998;83:11211127.

34. Chung JK, Park YJ, Kim TY, et al. Clinical Significance of elevated level of serum antithyroglobulin antibody in patients with differentiated thyroid cancer after thyroid ablation. Clin Endocrinol (Oxf). 2002;57: 215-221.

35. Ozata M, Suzuki S, Miyamoto T, Liu RT, Fierro- Renoy F, De Groot LJ. Serum thyroglobulin in the follow-up of patients with treated differentiated thyroid cancer. J. Clin Endocrinol Metab. 1994;79:98-105.

36. Pacini F, Lippi F. Clinical experience with recombinant human thyroid-stimulating hormone (rhTSH): serum thyroglobulin measurement. J Endocrinol Invest. 1999;22:25-29.

37. Torrens JI, Burch HB. Serum thyroglobulin measurement. Utility in clinical practice, Endocrinol Metab Clin North Am. 2001;30:429-467.

38. Singer Pa, Cooper DS, Daniels GH, Ladenson PW, Greenspan FS, Levy $\mathrm{EG}$, et al. Treatment guidelines for patients with thyroid nodules and well - differentiated thyroid cancer.
Arch Intern Med. 1996;156:21652172 .

39. Thyroid Carcinoma Task Force AACE/AAES medical/surgical guidelines for clinical practice: management of thyroid carcinoma. Endocr Pract. 2001;7:202-220.

40. Dunhill Sir TP: The surgery of the thyroid gland. Trans Med Soc Lond. 1937;60:234-282.

41. Balme HW. Metastastic carcinoma of the thyroid successfully treated with thyroxine. Lancet. 1954;266: 812-813.

42. Mazzaferri EL, Young RL, Oertel JE, Kemmerer WT, Page CO. Papillary thyroid carcinoma: The impact of therapy in 576 patients. Medicine 1977;56:171-196

43. Mazzaferri EL. Papillary thyroid carcinoma: Factors influencing prognosis and current therapy. Semin Oncol. 1987;14:315-332.

44. Ross DS, Neer RM, Ridgway EC, Daniels GH. 1987 Subclinical hyperthyroidism and reduced bone density as a possible result of prolonged suppression of pituitary-thyroid axis with 1-thyroxine. Am J Med. 1987; 82:1167-1170.

45. Paul TL, Kerrigan J, Kelly AM, Braverman LE, Baran DT. Longterm L-thyroxine therapy is associated with decreased hip bone density in premenopausal women. JAMA. 1988:259:3137-3141.

46. Faber J, Galloe AM. Changes in bone mass during prolonged subclinical hyperthyroidism due to Lthyroxine treatment: a meta-analysis. Eur J Endocrinol. 1994;130:350356.

47. Biondi B, Fazio S, Cuocolo A, Sabatini D, Nicolai E, Lombardi G, et al. Impaired cardiac reserve and exercise capacity in patients receiving long-term thyrotropin suppressive therapy with levothyroxine. J Clin Endocrinal Metab. 1996;81:42244228.

48. Parle JV, Maissoneuve P, Sheppard MC, Boyle P, Franklyn JA, Page CO. Prediction of all-cause and cardiovascular mortality in elderly people from one low serum thyrotropin result: a 10-year cohort study. Lancet. 2001; 358:861-865

49. Wang P-W, Wang S-T, Liu R-T, Chien W-Y, Tung S-C, Lu Y-C, et al. Levothyroxine suppression of 
thyroglobulin in patients with differentiated thyroid carcinoma. J Clin Endocrinol Metab. 1999;84:45494553.

50. Cailleux AF, Baudin E, Travagli JP, Ricard M, Schlumberger M. Is diagnostic iodine- ${ }^{131} \mathrm{I}$ scanning useful after total thyroid ablation for differentiated thyroid cancer? J Clin Endocrinol Metab. 2000;85:175-178.

51. Pacini F, Molinaro E, Lippi F, Castagna MG, Agate L, Ceccarelli $\mathrm{C}$, et al. Prediction of disease status by recombinant human TSH-stimulated serum $\mathrm{Tg}$ in the postsurgical follow-up of differentiated thyroid carcinoma. J Clin Endocrinol Metab. 2001;86:5686-5690.

52. Cooper DS, Doherty GM, Haugen BR, Kloos RT, Lee SL,Mandel SJ, et al. The American Thyroid Association Guidelines Taskforce. Management Guidelines for patients with thyroid nodules and differentiated thyroid cancer. Thyroid. 2006:16(2): 109-42.

53. Cooper DS, Specker B, Ho M, Sperling $\mathrm{M}$, Ladenson PW, Ross DS, etal. Thyrotropin suppression and disease progression in patients with differentiated thyroid cancer: results from the National Thyroid Cancer Treatment Cooperative Regisry. Thyroid 1998;8:737-744.

54. Tuttle RM, Brokhin M, Omry G, Martorella AJ, Larson SM, Grewal $\mathrm{RK}$, et al. Recombinant human TSHassisted radioactive iodine remnant ablation achives short-term clinical recurrence rates similar to those of traditional thyroid hormone withdrawal. J Nucl Med. 2008;49:764770

55. Cooper DS, Doherty GM, Haugen BR, Kloos RT, Lee LS, Mandel SJ, et al. Revised American Thyroid Association management guidelines for patients with thyroid nodules and differentiated thyroid cancer. Thyroid 2009;19(11):1167-1214.

56. Tsang RW, Brierley JD, Simpson WJ, Panzarella T, Gospodarowicz MK, Sutcliffe SB. The effects of surgery, radioiodine, and external radiation therapy on the clinical outcome of patients with differentiated thyroid carcinoma. Cancer. 1998; 82(2):375-88.

57. Farahati J, Reiners C, Stuschke M, Muller SP, Stuben G, Sauerwein W, et al. Differentiated thyroid cancer. Impact of adjuvant external radiotherapy in patients with perithyroidal tumor infiltration (stage pT4). Cancer. 1996;77(1):172-80.

58. Tubiana M, Haddad E, Schlumberger M, Hill C, Rougier P, Sarrazin D. External radiotherapy in thyroid cancers. Cancer 1985;55(9 Suppl):2062-71

59. Chow SM, Law SC, Mendenhall WM, Au SK, Chan PT, Leung TW, et al. Papillary thyroid carcinoma: prognostic factors and role of radioiodine and external radiotherapy. Int J Radiat Oncol Biol Phys. 2002; 52(3):784-95.

60. Philips P, hanzen C, Andry G, van HoutteP, Fruhling J. Postoperative irradiation for thyroid cancer. Eur J Surg Oncol. 1993;19:399-404.

61. Farahati J, Reiners C, Stuschke M, Muller SP, Stuben G, Sauerwein W, et al. Differentiated in patients with perithyroidal tumor infiltration (stage pT4). Cancer. 1996;77:17280.

62. Mazzaferri EL, Kloos RT. Clinical report 128: current approaches to primary therapy for papillary and follicular thyroid cancer. J Clin Endocrinol Metab. 2001;86(4):1447-63.

63. Cohen EG, Tuttle M, Kraus DH. Postoperative management of differentiated thyroid cancer. Otolaryngol Clin North Am. 2003; 36:129-57.

64. Chao Ma, Jiawei Xie, Anren Kuang. Is empiric $\mathrm{I}^{131}$ therapy justified for patients with positive thyroglobulin and negative $\mathrm{I}^{131}$ whole -body scanning results? J Nucl Med. 2005;46: 1164-1170.

65. Pineda JD, Lee T, Ain K, Reynolds J, Robbins J. Iodine-131 therapy for thyroid cancer patients with elevated thyroglobulin and negative scan. J Clin Endocrinol Metab. 1995;80: 1488-92.

66. Clark $\mathrm{OH}$, Hoelting T. Management of patients with differentiated thyroid cancer who have positive thyroglobulin levels and negative radioiodine scans. Thyroid 1994;4:501-5.

67. Brierley JD, Tsang RW. Externalbeam radiation therapy in the treatment of differentiated thyroid cancer. Semin Surg Oncol. 1999;16:429

68. McCaffrey JC. Evaluation and treatment of aerodigestive tract inva- sion by well differentiated thyroid carcinoma. Cancer Control. 2000; 7(3):246-252.

69. Shin DH, Mark EJ, Suen HC, Grillo HC. Pathologic staging of papillary carcinoma of the thyroid with airway invasion based on the anatomic manner of extension to the trachea: a clinicopathologic study based on 22 patients who underwent thyroidectomy and airway resection. Hum Pathol. 1993;24:866-870

70. Friedman $M$, Ibrahim $H$, Ramakrishnan V. Management of invasive thyroid carcinoma. Operative Techniques in Otolaryngology-Head Neck Surg. 2003;14(2):86-89.

71. Friedman M, Skolnik E, Baim HM, Becker SP, Katz AH, Mantravadi $\mathrm{RV}$, et al. Thyroid carcinoma. Laryngoscope. 1980;90:1991-2003.

72. Sheline GE, A' Hern RP, Galante M, Lindsay S. Radiation therapy in the control of persistent thyroid cancer. Am J Roentgenol Radium Ther Nucl Med. 1966;97:923-930

73. Clark JR, Fridman TR, Odell MJ, Brierley J, Walfish PG, Freeman JL. Prognostic variables and calcitonin in medullary thyroid cancer. Laryngoscope. 2005;115:1445-50.

74. Moley JF, DeBenedetti MK. Patterns of nodal metastases in palpable medullary thyroid carcinoma: Recommendations for extent of nodal dissection. Ann Surg. 1999;229: 880-7.

75. O'Riordain DS, O'Brien T, Weaver AL, Gharib H, hay ID, Grant CS, etal.Medullary thyroid carcinoma in multiple endocrine neoplasia types $2 \mathrm{~A}$ and 2B. Surgery. 1994;116:1017-23.

76. Cooper DS, Doherty GM, Haugen BR, Kloos RT, Lee SL, Mandel SJ, et al. Revised American Thyroid Association Management Guidelines for patients with thyroid nodules and differentiated thyroid cancer. Thyroid. 2009;19(11):1167-1214

77. Brandi Ml, Gagel RF, Angeli A et al. Guidelines for diagnosis and therapy of MEN type 1 and type 2. J Clin Endocrinol Metab. 2001;86: 5658-71.

78. Gill JR, Reyes-Mugica M, Iyengar $\mathrm{S}$, et al. Early presentation of metastatic medullary carcinoma in multiple endocrine neoplasia, type IIA: implications for therapy. J Pediatr Surg. 1996;129:459-64. 
79. Gimm O, Ukkat J, Niederl BE, et al. Timing and extent of surgery in patients with familial medullary thyroid carcinoma/multiple endocrine neopalsia 2A-related RET mutations not affecting codon 634. World J Surg. 2004; 28:1312-6.

80. Learoyd DL, Gosnell J, Elston MS, et al. Experience of prophylactic thyroidectomy in multiple endocrine neoplasia type 2A kindreds with RET codon 804 mutations. Clin Endocrinol. 2005;63:636-41.

81. Frank-Raue K,Raue F, Buhr HJ, Baldauf G, Lorenz D, Ziegler R. Localization of occult persisting me- dullary thyroid carcinoma before microsurgical reoperation: High sensitivity of selective venous catheterization. Thyroid. 1992;2(2):113117

82. Wells Jr SA, Chi DD, Toshima K, Dehner LP, Coffin CM, Dowton SB, et al. Predictive DNA testing and prophylactic thyroidectomy in patients at risk for multiple endocrine neoplasia type 2A.Ann Surg 1994; 220:237: discussion 247.

83. Byar DP, Green SB,Dor P, Williams ED, Colon J, van Gilse HA, et al. A prognostic index for thyroid carcinoma. A study of the E.O.R.T.C
Thyroid Cancer Cooperative Group. Eur J Cancer. 1979;15:10331041.

84. Cobin RH, Gharib H, Bergman DA, Clark OH, Cooper DS, Daniels GH, etal.: AACE/AAES medical/surgical guidelines for clinical practice: management of thyroid cancer. Endocr Pract. 2001;7:203-220.

85. Wilson PC, Millar BM, Brierley JD The management of advanced thyroid cancer. Clinical Oncology 2004; 16:561-568

86. Pasieka JL. Anaplastic thyroid cancer. Curr. Opin. Oncol. 2003;15: 78-83. 